\title{
A EDUCAÇÃO FÍSICA NO BRASIL DA DÉCADA DE 20: UMA ABORDAGEM CONTEXTUALIZADA
}

\author{
Aline Barbier \\ Charles Souza \\ Maiara Pagnan \\ Michele Vieira \\ Marcelo Filite
}

\section{Resumo}

A década de 20 foi um período de importantes acontecimentos no Brasil em todas as esferas sociais: política, econômica, artística-cultural e educacional. Tendo em vista tais aspectos, a seguinte pesquisa teve como objetivo analisar como a Educação Física estava inserida e foi influenciada por essas modificações sociais ocorridas nessa década. Para tanto, buscou-se apresentar uma visão contextualizada da Educação Física no Brasil na década de 1920, destacando os acontecimentos mais relevantes da época. Dentre as modificações mais significativas destacam-se, no campo econômico, os reflexos positivos de crescimento industrial ocasionado pela primeira grande guerra, bem como o início da dependência de capital norteamericano, acompanhado pela política do "café-com-leite", caracterizada pelo revezamento do poder nacional entre paulistas e mineiros. Esse quadro político-econômico influenciou significativamente a esfera artística-cultural brasileira na medida em que podemos visualizar o já crescente processo de importação cultural, principalmente provinda do povo norte-americano. $\mathrm{O}$ contexto político-econômico determinou profundas mudanças também no campo educacional, marcadas pelo início do movimento escolanovista ocorrido por conta, sobretudo, da necessidade de formação de um novo homem, ajustado às novas roupagens da sociedade que florescia. A respeito da Educação Física, o fato mais importante a ser destacado nessa época é a substituição de seu método alemão para o método da escola francesa.

\section{Palavras-Chave}

Década de 1920; Contexto Histórico; Educação Física.

\section{PHYSICAL EDUCATION IN BRAZIL THE DECADE 20: AN APPROACH CONTEXTUALISED}

\author{
Aline Barbier \\ Charles Souza \\ Maiara Pagnan \\ Michele Vieira \\ Marcelo Filite
}

\begin{abstract}
The decade of the 20 was a period of important events in Brazil in all spheres of society: political, economic, artistic, cultural and educational. Considering these aspects, the following research was to examine how physical education was part and was influenced by the social changes that occurred in this decade. To this end, we attempted to present a contextualized view of Physical Education in Brazil in the 1920s, highlighting the most relevant events of the season. Among the most significant changes stand out in the economic field, the positive impact of industrial growth caused by the first great war and the beginning of the dependence of U.S. capital, accompanied


by the policy of "café au lait", characterized the relay of national power between São Paulo and Minas Gerais. This political-economic framework has significantly influenced the artistic sphereBrazilian culture to the extent that we can already see the growing process of cultural importation, mainly stemmed from the American people. The political and economic context also determined profound changes in the educational field, marked the beginning of the School movement occurred due, mainly, the need to train a new man, new clothing tailored to the company flourished. Regarding Physical Education, the most important fact to be noted at this time is the replacement of its German method to the method of the French school.

\section{Key-Words}

1920s; Historical Context; Physical Education. 


\section{INTRODUÇÃO}

Antes de iniciarmos nossa viagem à década de 20, sentimos a necessidade de tecermos algumas considerações a respeito dos principais acontecimentos que antecederam esse período, a fim de entendermos o contexto histórico-social no qual essa década estava inserida.

O período que compreende os anos de 1889 a 1930 é conhecido como "República Velha" ou "Primeira República". Essa, a partir de 1894 passa a ser chamada também de República do Cafécom-Leite, devido ao domínio exercido no cenário político nacional pelos paulistas produtores de café e pelos mineiros pecuaristas, que revezavam a presidência da República. Marco importante em todo o período de República café-com-leite foi o "Coronelismo", um movimento de controle político local pelos latifundiários (coronéis) através da compra de votos, violência e fraudes (voto-de-cabresto) (PETTA; OJEDA, 1999).

Paralelamente a essa realidade brasileira, no final do século 19 e início do século 20, observa-se um processo de intensa urbanização, industrialização e expansão populacional. Esse momento de crescimento e desenvolvimento brasileiro refletiu-se nas artes como um período de grande entusiasmo e nacionalismo, como por exemplo, o declínio da tendência literária parnasianista e o florescimento do pré-modernismo nas artes e o movimento de "entusiasmo pela educação" no campo educacional (VILARINHO, 2009).

Durante a República café-com-leite, a educação nacional era voltada prioritariamente às elites, para a formação dos filhos dos burgueses, uma vez que a maioria da população encontrava-se fora do estabelecimento escolar (AZEVEDO, 2005).

Nessas instituições o ensino era pautado na Pedagogia Tradicional, que tornou-se hegemônica logo após a expulsão dos jesuítas do Brasil em 1759 (PASSOS; VEIGA, 1994; SAVIANI, 2000). Nessa nova pedagogia tradicional, instaurada para disseminar a visão burguesa de mundo, os alunos eram vistos como essencialmente iguais por serem dotados da mesma natureza, assim, caracterizavam-se por uma atitude de passividade: o professor falava sobre conteúdos clássicos e eruditos e seus alunos deveriam ouví-lo em silêncio, imóveis e de braços cruzados (PASSOS; VEIGA, 1994). O ensino estava centrado no professor, na transmissão de conhecimentos lógicos, assim, a didática resumia-se em dar e tomar a lição (CARMO, 1985; PASSOS; VEIGA, 1994). 
A Educação Física, durante quase toda a década de 20 seguiu o método alemão de ensino, sendo este substituído pelo francês em 1929 por ação do Ministério da Guerra (FILHO, 1988). Na chamada escola tradicional, ao aluno cabia apenas a repetição pura e simples dos gestos e movimentos, dentro de uma rigorosa disciplina. O professor realizava os movimentos à frente de seus alunos e estes os repetiam fielmente, mesmo desconhecendo todos os objetivos da ação prática. Se os alunos desobedecessem ao professor, eram punidos com carga excessiva de exercícios. O professor era um autêntico instrutor ou condicionador (CARMO, 1985).

Entre os anos 1914-1917 a $1^{\circ}$ Guerra Mundial influenciou significativamente nosso país gerando novas perspectivas em torno da situação econômica, política, cultural e educacional brasileira; como poderemos observar a seguir analisando os principais acontecimentos da década de 20 .

\title{
A POLÍTICA E A ECONOMIA DA ÉPOCA
}

A $1^{\circ}$ Guerra Mundial (1914-1917) ocasionou no Brasil um processo de grande crescimento e diversificação industrial, uma vez que, devido a crise instaurada nos países europeus, forçou o Brasil a substituir suas importações por produtos nacionais (BAER, 1996; PETTA; OJEDA, 1999). Logo, esse crescimento industrial teve de ser acompanhado pelo aumento no número de trabalhadores nas fábricas, dando início a um processo de intensa urbanização e imigração (PETTA; OJEDA, 1999). Sobre esse processo, Baer (1996, p. 47) considera:

\begin{abstract}
A força básica que apoiou esse desenvolvimento industrial foi o incremento cafeeiro baseado na mão-de-obra imigrante livre. Investimentos significativos voltados para a infra-estrutura que atendia ao setor cafeeiro (estradas de ferro, usinas elétricas, etc.), financiados por fazendeiros e capital estrangeiro, proporcionaram o ambiente para uma produção industrial local maior e aos poucos criaram uma demanda para peças de reposição produzidas internamente.
\end{abstract}

Junto desse crescimento industrial e aumento da mão-de-obra, aumentou-se também o número de greves e revoltas nacionais na busca por melhores condições de trabalho e de vida, como a Revolta da Vacina (1904, durante o governo de Rodrigues Alves), Revolta da Chibata (1910 no Rio de Janeiro), Guerra do Contestado (1912-1916).

A política que antecede a década de 20 é marcada por dois acontecimentos considerados aqui como principais: o Funding Loan e o Convênio de Taubaté. 
$\overline{\mathrm{O} \text { Funding Loan foi um acordo realizado por Campos Sales com os principais credores }}$ internacionais para o restabelecimento do crédito brasileiro no exterior, numa tentativa de estabilizar a economia brasileira. Esse acordo previa a suspensão por três anos do pagamento dos juros da dívida externa, bem como a suspensão por 13 anos do pagamento de suas parcelas. Contudo, essa estratégia para estabilização da economia teve efeito nocivo para o Brasil, tendo em vista que originou uma nova dívida a somar com a já existente. Outro aspecto prejudicial ao nosso país é que, como garantia, o governo brasileiro teve que entregar alguns os portos e alfândegas.

O Convênio de Taubaté, instaurado no governo de Rodrigues Alves (1902-1906), foi um acordo realizado entre o governo e os cafeicultores, com o objetivo de manter os preços do café através de intervenção estatal, compra de estoques excedentes, empréstimos estrangeiros e restrição a expansão dos cafezais.

A década de 20 se inicia com o governo de Epitácio Lindolfo da Silva (1919-1922), que depois é substituído por Artur da Silva Bernardes e Washington Luís Pereira de Souza. Nessa década, o Brasil estava vivendo a chamada política do café-com-leite (iniciada por Prudente de Moraes em 1894), nome originário do revezamento na presidência da República de paulistas, produtores de café e mineiros, produtores de leite (SENKEVICS, 1999; PETTA; OJEDA, 1999). A economia e a política eram assim comandadas pelas oligarquias agrárias exportadoras. O café era o principal produto exportado, de acordo com Baer (1996) a participação do café nas exportações aumentou de 56\% em 1919 para mais de $75 \%$ em 1924.

As oligarquias agrárias eram grupos políticos ligados à posse de terra, a agricultura de exportação e a defesa dos interesses da aristocracia rural. Por serem os estados que tinham as maiores propriedades rurais, São Paulo e Minas Gerais formaram, respectivamente, os partidos políticos PRM (Partido Republicano Mineiro) e PRP (Partido Republicano Paulista) e representavam as oligarquias de maior poderio nacional.

Para garantir o domínio político nacional nas mãos dos "café-com-leite", ou seja, o domínio estadual nas mãos das oligarquias rurais adotou-se no início do século XX, a chamada Política dos Governadores. Essa política constitui-se de um acerto realizado entre o governo federal e Conexões: revista da Faculdade de Educação Física da UNICAMP, Campinas, v. 8, n. 1, p. 182-199, jan./abr. 186 2010. ISSN: $1983-930$ 
governos estaduais, iniciado pelo presidente Campos Sales (1889-1902) que funcionou como uma troca de favores entre o chefe da nação e os presidentes dos estados.

Outro movimento que marcou a década de 20 foi o "Coronelismo" que caracterizou-se pelo controle da política local pelos latifundiários (coronéis) através de "favores" prestados aos eleitores, violência e fraudes (voto-de-cabresto), mantendo no poder os representantes das classes dominantes (PETTA; OJEDA, 1999).

O Tenentismo foi um movimento político-militar liderado por jovens oficiais oriundos da classe média e representou a forma mais organizada de reação ao domínio oligárquico. Sem doutrina ou ideologia bem definida, exigia reformas políticas que acabassem com o domínio das oligarquias e dos coronéis. Houve o primeiro e frustrado levante tenentista, a Revolta dos Dezoito do Forte de Copacabana, originado das disputas entre o candidato café-com-leite Artur Bernardes e Nilo Peçanha representante das oligarquias dissidentes (PETTA; OJEDA, 1999).

No período de 1922 a 1926 ocorre uma crise econômica nacional acompanhada de intensos conflitos políticos e revoltas armadas. Em 1922 tem-se a fundação do Partido Comunista Brasileiro (PCB). Logo, Artur Bernardes, presidente atuante, governou o Brasil valendo-se de um dispositivo constitucional denominado "estado de sítio" que aumentou o poder do governo e diminuiu o das classes populares.

\footnotetext{
O estado de sítio se caracteriza por um momento de ausência de normalidade política, geralmente provocado por situações de grave crise nacional, em que são suprimidas as leis que garantem os direitos do cidadão perante o Estado. Dessa forma, o governante adquire total autoridade perante a nação (PETTA; OJEDA, 1999, p. 227).
}

Contra essa repressão tem-se, também nessa década, um dos movimentos tenentistas mais importantes: a Coluna Prestes, que formou-se da união da Coluna Paulista com a Coluna Gaúcha. Comandada por Luís Carlos Prestes, no ano de 1925, os participantes dessa Coluna fizeram uma marcha pelo interior do país, que durou quase dois anos, com o objetivo de difundir na população os ideais contra o governo oligárquico. Em 1927, frustrados por não terem conseguido a adesão do povo brasileiro, os participantes da Coluna Prestes refugiaram-se na Bolívia e deram fim a sua marcha revolucionária (PETTA; OJEDA, 1999; SENKEVICS, 2009). 
$\bar{O}$ último presidente da República Velha foi Washington Luís Pereira de Sousa (1926-1930). Em seu governo aconteceram várias disputas entre oligarquias e a decadência das exportações de café, devido à crise de 1929 (crise da superprodução cafeeira) gerada pela quebra da bolsa de valores de Nova York, que fortaleceram o declínio do poder oligárquico e o golpe de 1930.

Em 1928 começou a se delinear o risco de a classe dominante, as elites agrárias, terem que dividir o seu poder com outras camadas da sociedade. Em 1929 houve uma ruptura na estrutura cafécom-leite: o paulista Washington Luís, então presidente da República, deveria indicar o mineiro Antônio Carlos para seu sucessor. Contudo, Washington Luís indica o paulista Júlio Prestes, decretando o conflito entre as oligarquias paulista e mineira.

Assim, em meio a um contexto bastante conturbado acontece o golpe de Getúlio Vargas em 1930 que teve como pretexto a suspeita de fraude na eleição de 1929. Petta e Ojeda (1999) consideram que o Movimento de 30 acabou com a hegemonia dos cafeicultores no controle do governo federal, contudo, pôs fim também, às forças progressistas que pretendiam criar um Estado democrático após a queda das oligarquias.

\section{ASPECTOS ARTÍSTICO-CULTURAIS}

A década de 20 também na perspectiva artística-cultural foi um período de grandes acontecimentos em âmbitos nacional e internacional. Já no início do século 20, apresentava-se evidente a ligação (por determinantes sócio-econômicos) do Brasil com os países estrangeiros. Tal atrelamento, produziu em nosso país uma cultura massivamente importada, como fica claro, principalmente, na análise das vestimentas e produção musical da população da época. Essa situação obteve como resposta, ou conseqüência, a chamada Semana de Arte Moderna, onde vários artistas procuraram resgatar e produzir uma cultura que fosse essencialmente brasileira.

\section{AS VESTIMENTAS}

A população mundial dessa época, além da ópera ou do teatro, também freqüentava os cinematógrafos, que exibiam os filmes de Hollywood e seus astros, como Rodolfo Valentino e Douglas Fairbanks. No Brasil da década de 20 chegam dos Estados Unidos os primeiros filmes sonoros, que se tornaram um sucesso imediato (CHAMBEL, 2009). Com isso, as mulheres 
copiavam os costumes de atrizes famosas, como Gloria Swanson e Mary Pickford, marcando a influência da cultura estrangeira em nosso país.

Garcia (2009) salienta que, livre dos espartilhos, usados até o final do século 19, a mulher começava a ter mais liberdade na década de 20 e já se permitia mostrar as pernas, o colo e usar maquiagem. A boca era carmim, pintada para parecer um arco de cupido ou um coração; os olhos eram bem marcados, as sobrancelhas tiradas e delineadas a lápis; a pele era branca, o que acentuava os tons escuros da maquiagem.

A silhueta dos anos 20 era tubular, com os vestidos mais curtos, leves e elegantes, geralmente em seda, deixando braços e costas à mostra, o que facilitava os movimentos frenéticos exigidos pelo Charleston: dança vigorosa, com movimentos para os lados a partir dos joelhos. As meias eram em tons de bege, sugerindo pernas nuas. O chapéu, até então acessório obrigatório ficou restrito ao uso diurno. O modelo mais popular era o "cloche", enterrado até os olhos, que só podia ser usado com os cabelos curtíssimos, a "la garçonne", como era chamado (GARCIA, 2009).

Diferentemente de hoje, a mulher sensual era aquela sem curvas, seios e quadris pequenos, sendo que a atenção estava toda voltada aos tornozelos. Em 1927, Jacques Doucet (1853-1929), figurinista francês, subiu as saias a ponto de mostrar as ligas rendadas das mulheres - um verdadeiro escândalo aos mais conservadores.

\section{AS MÚSICAS}

Durante a década de 1910, foram gravadas algumas composições sob a denominação de samba, mas estas gravações não alcançaram grande repercussão. No entanto, em 1917, foi gravado em disco "Pelo Telefone", aquele que é considerado o primeiro samba. A canção tem a autoria reivindicada por Ernesto dos Santos, o Donga, com co-autoria atribuída a Mauro de Almeida, um então conhecido cronista carnavalesco. Na verdade, "Pelo Telefone" era uma criação coletiva de músicos que participavam das festas da casa de tia Ciata, mas acabou registrada por Donga e Almeida na Biblioteca Nacional (SENKEVICS, 2009).

"Pelo Telefone" foi a primeira composição a alcançar sucesso com a marca de samba e contribuiria para a divulgação e popularização do gênero. A partir daquele momento, o samba começou a se espalhar pelo país, inicialmente associado ao carnaval e posteriormente adquirindo um lugar próprio no mercado musical. Surgiram muitos compositores como Heitor dos Prazeres, 
João da Baiana, Pixinguinha e Sinhô, mas os sambas destes compositores eram "amaxixados", conhecidos como sambas-maxixe.

Os contornos modernos do sambam viriam somente no final da década de 1920, a partir das inovações de um grupo de compositores dos blocos carnavalescos dos bairros do Estácio de Sá e Osvaldo Cruz, e dos morros da Mangueira, Salgueiro e São Carlos. Desde então, surgiriam grandes nomes do samba, como: Ismael Silva, Cartola, Ari Barroso, Noel Rosa, Ataulfo Alves, Wilson Batista, Geraldo Pereira, Zé Kéti, Ciro Monteiro, Nelson Cavaquinho, Elton Medeiros, Paulinho da Viola, Martinho da Vila, entre muitos outros.

Apesar do preconceito por suas origens negras, o samba se consolidou como uma expressão urbana e moderna, e passou a ser tocado nas rádios.

Derivadas do samba, outras formas musicais ganharam denominações próprias, como o samba de gafieira, o samba enredo, o samba de breque, o samba-canção, o samba-rock, o partido alto, o pagode, entre outros. Em 2007, o Iphan declarou o samba um Patrimônio Cultural do Brasil. O samba, além de ser o gênero musical mais popular no Brasil, é muito conhecido no exterior e está associado - assim como o futebol e o carnaval - ao país. Esta estória começou com o sucesso internacional de "Aquarela do Brasil", de Ary Barroso, seguiu com Carmen Miranda (apoiada pelo governo Getúlio Vargas e a política da boa vizinhança norte-americana), que levou o samba para os Estados Unidos, passou ainda pela Bossa Nova, que inseriu definitivamente o Brasil no cenário mundial da música. Outro gênero musical que se desenvolveu na década de 20 foi o Choro, popularmente chamado de chorinho, é um gênero musical, uma música popular e instrumental brasileira, com mais de 130 anos de existência. Os conjuntos que o executam são chamados de regionais e os músicos, compositores ou instrumentistas, são chamados de chorões. Apesar do nome, o gênero é em geral de ritmo agitado e alegre, caracterizado pelo virtuosismo e improviso dos participantes, que precisam ter muito estudo e técnica, ou pleno domínio de seu instrumento. O choro surgiu provavelmente em meados de 1870, no Rio de Janeiro, e nesse início era considerado apenas uma forma abrasileirada dos músicos da época tocarem os ritmos estrangeiros, que eram populares naquele tempo, como os europeus xote, valsa e principalmente polca, além dos africanos como o lundu. O flautista Joaquim Calado é considerado um dos criadores do Choro, ou pelo menos um dos principais colaboradores para a fixação do gênero, quando incorporou ao solo de flauta, dois violões e um cavaquinho, que improvisavam livremente em torno da melodia, uma característica do Choro moderno, que recebeu forte influência dos ritmos que no início eram somente interpretados, demorando algumas décadas para ser considerado um gênero musical.

Alguns dos chorões mais conhecidos são: Chiquinha Gonzaga, Ernesto Nazareth e Pixinguinha. Alguns dos choros mais famosos são: "Tico-Tico no Fubá", de Zequinha de Abreu; "Brasileirinho", de Waldir Azevedo, "Noites Cariocas", de Jacob do Bandolim; "Carinhoso", de Pixinguinha; "O violão e a flor", de Toninho Ramos.

A partir da década de 20 a música popular brasileira começa a sofrer a forte influência da música comercial norte-americana, fazendo com que muitos instrumentistas de choro parassem de tocar e outros aderissem os grandes “jazz-bans”.

\section{A SEMANA DE ARTE MODERNA}

A Semana de Arte Moderna foi o grande marco artístico-cultural do Brasil da década de 20, sendo realizada entre os dias 11 e 18 de fevereiro de 1922 no Teatro Municipal de São Paulo.

Conexões: revista da Faculdade de Educação Física da UNICAMP, Campinas, v. 8, n. 1, p. 182-199, jan./abr. 
$\overline{\text { Esse grande movimento contou com a participação de escritores, artistas plásticos, arquitetos } \mathrm{e}}$ músicos com propósitos de renovar o ambiente artístico e cultural do país com "a perfeita demonstração do que há em nosso meio em: escultura, arquitetura, música e literatura sob o ponto de vista rigorosamente atual", como informava o Correio Paulistano a 29 de janeiro de 1922 (MACHADO; AMARAL; LOURES, 2008, p. 2). Essa semana marcou a transição do PréModernismo para o Modernismo e dentre os participantes da Semana de Arte Moderna estavam: o escritor Menotti del Picchia, Mário de Andrade, Oswald de Andrade, Graça Aranha e Ronald de Carvalho; os pintores Di Cavalcanti, Anita Malfati, Yan de Almeida Prado, John Graz e Zina Aita; os escultores Vitor Brecheret e Wilheim Haaberg; os compositores Heitor Vila-Lobos e Ernani Braga (PETTA; OJEDA, 1999).

O momento de intensa prosperidade econômica em qual estava o Brasil nessa década, fez com que muitos artistas sentissem a necessidade de se contraporem à produção artística-cultural da época, tendo em vista a forte influência estrangeira na forma como os brasileiros se vestiam, agiam, ouviam músicas, enfim, produziam arte.

Buscou-se nesse momento o que era verdadeiramente brasileiro, a fim de se construir uma identidade nacional. No universo educacional brasileiro, esse movimento exerceu influência significativa, principalmente, com o movimento de "entusiasmo pela educação", que abordaremos mais detalhadamente a seguir.

\section{A EDUCAÇÃO NA DÉCADA DE 20}

A Primeira Guerra Mundial proporcionou um grande crescimento econômico no Brasil, afetando o quadro político e educacional de nosso país (SOARES; SILVA, 2007; PETTA; OJEDA, 1999). O movimento de "entusiasmo pela educação" pode ser considerado um grande exemplo no panorama educativo de tal influência. Passos e Veiga (1994) consideram que esse movimento constituiu-se de um processo de valorização e difusão da educação, bem como de combate ao analfabetismo. Analisando o contexto histórico-social da época, fica claro que tanto o movimento de "entusiasmo pela educação" como o de "combate ao analfabetismo" são resultantes, respectivamente, do crescimento industrial e consequente necessidade de mão-de-obra minimamente qualificada; e da necessidade dos grandes latifundiários em aumentarem o seu 
$\overline{\text { número de eleitores }^{1} \text {. O problema do analfabetismo era visto também, como uma vergonha }}$ nacional, e assim, o movimento contra o analfabetismo veio contribuir em mais um aspecto, uma vez que se tinha a crença de que se essa vergonha nacional fosse eliminada o Brasil seria capaz de igualar-se aos países desenvolvidos (PASSOS; VEIGA, 1994).

Como resultado desse movimento de "entusiasmo pela educação" e de prosperidade nacional, surge uma nova teoria da educação, pautada num ensino prático com vistas a superar o atraso e a ignorância popular (GIORGI, 1986). Essa teoria ficou conhecida como Pedagogia Nova ou Escola Nova e foi um marcante acontecimento no âmbito educacional do Brasil na década de 20, contrapondo-se à Escola Tradicional vigente.

Essa Pedagogia Nova teve origem norte-americana, tendo como idealizador principal o filósofo e pedagogo John Dewey (1859-1952) (HAMZE, 2007). Ele acreditava que o ensino deveria se dar pela ação e não pela instrução, porque a educação se dava continuamente pela experiência concreta, ativa e produtiva de cada um (SOARES; SILVA, 2007). O aprendizado, de acordo com Dewey, aconteceria mediante cinco estágios:

$1^{\circ}$ ) uma necessidade sentida;

$2^{\circ}$ ) a análise da necessidade;

$3^{\circ}$ ) as alternativas de solução do problema;

$4^{\circ}$ ) a experimentação de várias soluções;

$\left.5^{\circ}\right)$ a ação final de maneira científica.

Os ideais da Escola Nova chegaram ao Brasil no governo do presidente Artur Bernardes (período da república café-com-leite - 1922) e tiveram como representante principal Anísio Teixeira, grande seguidor das idéias deweyanas.

No contexto de declínio das oligarquias em decorrência das mudanças na estrutura econômica, em 1924 foi fundada a ABE (Associação Brasileira de Educação) onde se reuniram os educadores adeptos à Escola Nova. Logo, várias reformas escolares foram realizadas pelo Brasil a fim de estabelecer os ideários da nova pedagogia: 1920 em São Paulo (Sampaio Dória); 1922-

\footnotetext{
${ }^{1}$ Nos grandes latifúndios só podiam votar aqueles que eram alfabetizados, ou menos, sabiam assinar o nome. Assenta-se aí o interesse dos coronéis no movimento contra o analfabetismo. A respeito consultar Petta e Ojeda, 1999.

Conexões: revista da Faculdade de Educação Física da UNICAMP, Campinas, v. 8, n. 1, p. 182-199, jan./abr.

192 
1923 no Ceará (Lourenço Filho); em 1924 na Bahia (Anísio Teixeira); 1925-1928 no Rio Grande do Norte (José Augusto Bezerra de Menezes); 1927-1928 no Paraná (Lisímaco Costa); 19271928 em Minas Gerais (Francisco Campos); 1928 no Pernambuco (Carneiro Leão); 1927-1930 no Distrito Federal (Fernando de Azevedo) (GIORGI, 1986; HAMZE, 2007; SOARES; SILVA, 2007). Em 1932, acontece o Manifesto dos Pioneiros da Educação Nova, que se foi um documento que reinvidicava politicamente, uma maior atuação do Estado em benefício do desenvolvimento de uma escola pública, universal, gratuita e laica (SOARES; SILVA, 2007).

A pedagogia Nova veio propor uma escola onde a educação deveria ressaltar as diferenças individuais, ajustando e incorporando os sujeitos à sociedade industrial (SAVIANI, 1983; GIORGI, 1986). Todo aluno deveria ser educado até onde permitia suas aptidões naturais, independentemente de razões econômicas e sociais, em suma, a Escola Nova veio instaurar o que Lage (2008, p. 1) chama de uma "democratização educacional". Giorgi (1986, p. 71) afirma que enquanto a educação tradicional era entendida como adaptada a uma sociedade estática:

\footnotetext{
A Escola Nova seria a educação adaptada à sociedade industrial que se transformava a todo momento. Uma das expressões mais caras aos escolanovistas é "educação para uma sociedade em mudança”. Assim, seus métodos são voltados para formar indivíduos ativos, preparados para enfrentar as mudanças que sofrerão ao longo de suas vidas.
}

Nessa perspectiva o centro do processo de ensino-aprendizagem desloca-se do professor (escola tradicional) para o aluno, sendo que o conhecimento deveria ser assimilado por meio da aquisição individual realizada por meio de experiências, observações de fatos e objetos. A aquisição da escrita se tornou imprescindível para o desenvolvimento dos indivíduos (LAGE, 2008; GIORGI, 1986). Com isso, todas as escolas deveriam ser muito bem equipadas e providas de laboratórios. O professor nesse quadro passa a ter papel de estimulador e orientador, pois toda iniciativa deveria partir do interesse da criança, e todo aprendizado provinha da experiência do aluno (GIORGI, 1986). Tratava-se de uma nova pedagogia pautada na psicologia, que tinha uma visão de educação como processo e não como produto.

Carmo (1985) contribui de forma interessante na nossa análise sobre a pedagogia Nova, o autor salienta que é clara a ligação desse modelo educacional com as necessidade política-econômicas burguesas, uma vez que as idéias norteadoras dessa nova pedagogia foram fundamentadas no liberalismo econômico. 
Dentre as contribuições da Escola Nova, Giorgi (1986) destaca: a valorização da infância, da liberdade, do interesse e da iniciativa nas escolas. Em contrapartida, o autor ainda considera que essa escola acabou contribuindo à burguesia de forma notável. Ao dar ênfase aos métodos, aos materiais de pesquisa, e não aos conteúdos, a Escola Nova aprimorou o ensino das elites e defasou ainda mais o ensino popular.

Carmo (1985) destaca que a luta entre o novo pensamento escolanovista e o tradicional durou até por volta de 1945, quando o pensamento escolanovista se torna hegemônico.

\section{A EDUCAÇÃO FÍSICA NESSE CONTEXTO}

A prática da educação física, assim como outras disciplinas, sofreu e sofre influência de várias tendências pedagógicas, as quais são determinadas pelas necessidades sócio-econômicas da sociedade.

Ela adentrou na educação brasileira com fins militares e higiênicos, no Brasil Império a grande maioria dos trabalhos sobre Educação Física, devem-se ao Colégio do Rio de Janeiro (Faculdade de Medicina), que exigia dos candidatos ao diploma de doutor em medicina, uma tese obrigatória. Influenciados pelas teorias de Rousseau e Spencer, muitos dos doutorandos escolhiam a Educação Física como tema de suas teses (FILHO, 1988; CARMO, 1985).

Soares (2001) diz estar a História da Educação Física no Brasil, se confundindo em muitos momentos, com a das instituições médicas e militares. Desde a criação da Academia Real Militar em 1810 (dois anos após a chegada da Família Real no Brasil), passando pela fundação da Escola de Educação Física da Força Policial do Estado de São Paulo, em 1910 (o mais antigo estabelecimento especializado em todo o país), até a criação do Centro Militar de Educação Física, em 1922, criado à partir de uma portaria do Ministério da Guerra, somados a outros fatos, marcaram a presença dos militares na formação dos primeiros professores civis de Educação Física. Apenas no de 1939 foi criada a primeira escola civil de formação de professores de educação física (SOARES et al, 1996).

Assim, a Educação Física no Brasil foi marcada, no início, pela ação dos militares que, por sua vez, foram influenciados pelos princípios positivistas que tinham por objetivo a manutenção da ordem social para termos "Progresso e Desenvolvimento" do país. Para este progresso era 
necessário então formar um indivíduo forte e saudável, "o corpo do indivíduo, como mais um instrumento da produção, passava a constituir uma preocupação da classe no poder (...) era preciso adestrá-lo, desenvolver-lhe o vigor físico desde cedo... discipliná-lo, enfim, para sua função na produção e reprodução do capital" (SOARES, 2001, p.33; SOARES et al, 1996).

A tendência higienista, que era educar o físico para se obter a saúde corporal, determinava a visão dos exercícios físicos como sendo "receita" e "remédio" para as "doenças" sociais (SOARES et al, 1992). Isso se deve a grande participação dos médicos da época, que influenciaram nos padrões de conduta física, moral e intelectual da sociedade.

E a educação, particularmente a escolar, constitui espaço privilegiado de veiculação destes valores e normas de "bem viver". A influência exercida pelos médicos no pensamento e na prática educacional brasileira, de fato, foi marcante e acentuou-se ao longo de todo o século XIX, para tornar-se determinante nas primeiras décadas do século XX (SOARES, 2001, p.82).

No Brasil nas quatro primeiras décadas do século XX foi marcante no sistema educacional a influência dos métodos ginásticos e da instituição militar. A educação física era vista como uma atividade apenas prática (SOARES et al, 1996).

Como a prática da Educação Física escolar basicamente iniciou-se com o militarismo e o higienismo, estes possuíam dentro da pedagogia tradicional uma importância na formação do corpo vigoroso e saudável para formar o indivíduo "forte" e apto para o trabalho e para o cumprimento das obrigações militares. As atividades físicas praticadas na escola eram iguais as utilizadas nos quartéis, com ampla utilização dos métodos ginásticos europeus e ênfase acentuada nos exercícios calistênicos, que são repetitivos, seqüenciais, formativos e militarizantes que objetivavam o desenvolvimento das qualidades físicas como: força, velocidade, agilidade, ritmo, etc. Alguns exemplos desses exercícios são o "poli-chinelo", a flexão de braço e o abdominal.

O professor de educação física era visto como apenas um transmissor destes conteúdos, o que faziam com que as aulas não fossem motivantes ou despertassem o prazer pela prática, o aluno deveria apenas reproduzir e executar corretamente os movimentos orientados pelo professor, de maneira passiva e disciplinada, semelhante realmente a um quartel (CARMO, 1985; FILHO, 1988). Tanto que para isso, algumas "vozes de comando" eram utilizadas na Pedagogia Tradicional, como "esquerda ou direita volver" ou "posição de sentido". Caso o aluno tivesse um desempenho físico-motor insatisfatório era reprovado. Desta maneira o aluno não desenvolvia 
sua criatividade de expressão corporal, pois era formado para cumprir as funções criadas pelo sistema.

$\mathrm{Na}$ década de 20 foram realizadas várias reformas educacionais que contemplavam a educação física como componente curricular do ensino primário e secundário. Houve também, algo que podemos considerar como mais um reflexo da Primeira Guerra Mundial², uma mudança na questão do método, que antes era o método alemão, introduzido no Brasil em 1860, e passa ser o método francês. Corroborando com tal afirmação Carmo (1985, p. 37) considera que:

Enquanto as idéias escolanovistas sedimentaram-se em outras áreas do conhecimento, apesar da luta entre seus seguidores e tradicionalistas, no campo da Educação Física, neste mesmo período, qual seja, a década de 20 , a grande mudança ocorrida foi a substituição do método alemão pelo francês.

Essa troca foi devida a um anteprojeto de lei originado pelo Ministério da Guerra em 1929 que, além disso, determinava a prática da educação física para todos residentes do Brasil e definindo caráter obrigatório em estabelecimentos de ensino a partir dos seis anos de idade (FILHO, 1988).

\section{CONSIDERAÇÕES FINAIS}

Vários acontecimentos antecedentes à década de 20, dentre eles a $1^{\circ}$ Guerra Mundial, que se destacou como um dos mais importantes, teceram o pano de fundo histórico em que essa década se iniciou. Novas perspectivas sócio-econômicas tomaram conta da sociedade brasileira desse período, que acabaram por se refletir na música, nos costumes e também na prática pedagógica escolar.

Como pudemos observar, a música nacional, assim como as vestimentas, já nas primeiras décadas do século 20, funcionaram como um verdadeiro termômetro artístico-cultural, evidenciando as raízes do nosso processo de importação cultural, principalmente americana, como resultado da já existente dependência nacional de capital estrangeiro.

Nesse momento de consolidação e desenvolvimento da sociedade de classes brasileira, a instituição escolar, e inserida nela, a Educação Física, como aparelhos ideológicos burgueses, não poderiam deixar de acompanhar o movimento social capitalista. Assim, tiveram de se reajustar às

\footnotetext{
${ }^{2}$ Em 1917 o Brasil declara seu apoio à Tríplice Entente, composta por Inglaterra, França e Rússia em oposição à Tríplice Aliança composta pela Alemanha, o Império Austro-Húngaro e a Itália. Nesse sentido, a permanência do método alemão no território brasileiro perdeu o sentido. A respeito, consultar Petta e Ojeda (1999). 
necessidades sociais vigentes para se manterem úteis, como se observa com a tendência escolanovista em substituição à tradicional, e o método francês em substituição ao alemão, respectivamente.

\section{REFERÊNCIAS}

AZEVEDO, C. P. Concepção do sistema escolar brasileiro entre a década de 20 e 30 expressa na visão de Anísio Teixeira. Revista da UFG, v. 7, n. 2, dez. 2005. Disponível em: http://www.proec.ufg.br/revista_ufg/45anos/B-sistemaescolar.html. Acesso em 03 de janeiro de 2010.

BAER, W. A Economia Brasileira: uma breve análise desde o período colonial até a década de 1970. $2^{\circ}$ ed. 1996.

CARMO, A. A. Educação Física: Competência Técnica e Consciência Política em busca de um Movimento Simétrico. Uberlândia, 1985.

CHAMBEL, R. A Era do Sonoro. In: História do Cinema: 1920-1929. 2009. Disponível em: http://www.chambel.net/?p=41. Acesso em: 03 de jan. 2010.

FILHO, L. C. Educação Física no Brasil: A história que não se conta. Coleção Corpo e Motricidade. Campinas: Papirus, 1988.

GARCIA, C. Anos 20: A Era do Jazz. Especial Moda. 2009. Disponível em: $<$ http://almanaque.folha.uol.com.br/anos20.htm>. Acesso em: 03 de jan. 2010.

GIORGI, C. D. Escola Nova. Série Princípios. São Paulo: Ática, 1986.

HAMZE, A. Escola Nova e o Movimento de Renovação do Ensino. Barretos. 2007. Disponível em: http://www.educador.brasilescola.com/gestao-educacional/escola-nova.htm. Acesso em: 03 jan. 2010.

LAGE, A. C. P. Pedagogia Escolanovista. 2008. Disponível em: $<$ http://www.histedbr.fae.unicamp.br/navegando/glossario/verb_c_pedagogia_escolanovista.htm. Acesso em: 03 jan. 2010.

PASSOS, I.; VEIGA, A. A prática pedagógica do professor de didática. $3^{\circ}$ ed. Campinas, SP: Papirus, 1994.

PETTA, N. L.; O. E. A. B. História: Uma Abordagem Integrada. Volume Único. 1. ed. São Paulo: Moderna, 1999. 
SENKEVICS, A. História e MPB no século XX: Café-com-leite. Abr. 2009. Disponível em: http://letrasdespidas.wordpress.com/2009/04/27/historia-e-mpb-no-seculo-xx-cafe-com-leite-i/. Acesso em: 03 jan. 2010.

SOARES, C. L.; TAFFAREL, C. N.; VARJAL, E.; et al. Metodologia do Ensino da Educação Física: a questão da organização do conhecimento e sua abordagem metodológica. In: Metodologia do Ensino de Educação Física. São Paulo, Cortez, 1992.

SOARES, C. L. Educação física: raízes européias e Brasil. Campinas, SP: Autores Associados, 2001.

SOARES, M. L. A.; SILVA, L. N. A Década de 20, o advento da Escola Nova e o Pensamento da Igreja Católica: O Caso do manual Literaturas Estrangeiras. Revista HISTEDBR On-Line. Campinas, n. 27, p. 143-148, set. 2007.

VILARINHO, Sabrina. Pré-Modernismo. 2009. Disponível em: http://www.brasilescola.com/literatura/pre-modernismo.htm. Acesso em: 03 de janeiro de 2010. 


\begin{abstract}
Aline Barbier
Universidade Estadual de Maringá

alinefb_90@yahoo.com.br

Charles Souza

Universidade Estadual de Maringá

charles_bsas@hotmail.com

Maiara Pagnan

Universidade Estadual de Maringá

maiara_toqueiro@hotmail.com

Michele Vieira

Universidade Estadual de Maringá

michele_1380@hotmail.com

\section{Marcelo Filite}

Universidade Estadual de Maringá

m_filite@hotmail.com
\end{abstract}

\title{
Referência de artigo
}

ABNT

BARBIER, A.; et al. A educação física no brasil da década de 20: uma abordagem contextualizada Conexões, v. 8, n.1, 2010

APA

Barbier, A., Souza, C. Pagnan, M. \& Vieira M. Filite M. (2010). A educação física no brasil da década de 20: uma abordagem contextualizada. Conexões, 8(1), 182-199

\section{VANCOUVER}

Barbier A, Souza C, Pagnan M, Vieira M, Filite M, A 182-199. A educação física no Brasil da década de 20: uma abordagerm contextualizada . Conexões, 2010; 8(1): 182-199.

Artigo recebido em 22 mar. 2010

Aceito para publicação em: 15 mar. 2010 